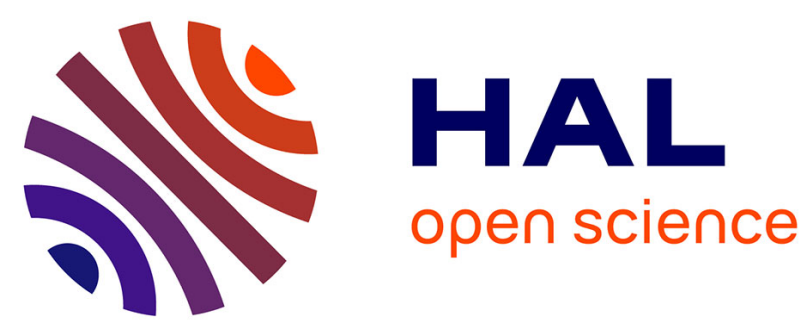

\title{
A solid phase-assisted approach for the facile synthesis of a highly water-soluble zirconium-89 chelator for radiopharmaceutical development
}

\author{
Manon Briand, Margaret L Aulsebrook, Thomas L Mindt, Gilles Gasser
}

\section{To cite this version:}

Manon Briand, Margaret L Aulsebrook, Thomas L Mindt, Gilles Gasser. A solid phase-assisted approach for the facile synthesis of a highly water-soluble zirconium-89 chelator for radiopharmaceutical development. Dalton Transactions, 2017, 46 (47), pp.16387-16389. 10.1039/c7dt03639f . hal-02378603

\section{HAL Id: hal-02378603 \\ https://hal.science/hal-02378603}

Submitted on 25 Nov 2019

HAL is a multi-disciplinary open access archive for the deposit and dissemination of scientific research documents, whether they are published or not. The documents may come from teaching and research institutions in France or abroad, or from public or private research centers.
L'archive ouverte pluridisciplinaire HAL, est destinée au dépôt et à la diffusion de documents scientifiques de niveau recherche, publiés ou non, émanant des établissements d'enseignement et de recherche français ou étrangers, des laboratoires publics ou privés. 


\title{
A solid phase-assisted approach for the facile synthesis of a highly water-soluble zirconium-89 chelator for radiopharmaceutical development
}

\author{
Manon Briand, ${ }^{a, \#}$ Margaret L. Aulsebrook, ${ }^{b, \#}$ Thomas L. Mindt, ${ }^{c, d, *}$ and Gilles Gasser, ${ }^{b, *}$ \\ Department of Chemistry, University of Zurich, Wintherthurerstrasse 190, CH-8057 Zurich, \\ Switzerland.
}

\begin{abstract}
a. Department of Chemistry, University of Zurich, Wintherthurerstrasse $190, \mathrm{CH}$ 8057 Zurich, Switzerland.

b. Chimie ParisTech, PSL Research University, Laboratory for Inorganic Chemical Biology, F-75005 Paris, France.

c. Department of Biomedical Imaging and Image Guided Therapy, Division of

Nuclear Medicine, Medical University of Vienna, Währinger Gürtel 18-20, AT-1090

Vienna, Austria.

d. Ludwig Boltzmann Institute Applied Diagnostics, General Hospital of Vienna, Währinger Gürtel 18-20, AT-1090 Vienna, Austria.

\# have contributed equally to the work

Corresponding authors: Email: t.mindt@gmx.ch; http://www.applieddiagnostics.at/team-imaging-biomarkers/; Tel. +43 14040025 35; Email:

gilles.gasser@chimie-paristech.fr; www: www.gassergroup.com; Tel.: +331442756

02.

Electronic Supplementary Information (ESI) available: [details of any supplementary information available should be included here]. See DOI: 10.1039/x0xx00000x
\end{abstract}

Nuclear medicine has seen impressive growth in recent years. An important development in this field was through the application of new radionuclides, e.g., ${ }^{89} \mathrm{Zr}\left(\mathrm{t}_{1 / 2}=78.4 \mathrm{~h}, 6+\right.$ $0.396 \mathrm{MeV}$ ), the physical properties of which allows the use of antibodies as biological vectors for specific cancer targeting in combination with high resolution imaging by positron emission tomography (PET). The most commonly used chelator for ${ }^{89} \mathrm{Zr}$-based PET imaging is the hexadentate desferrioxamine (DFO) chelator. However, due to the instability of this complex, there has been a strong push towards the development of octadentate chelators. We report an ether derivative, oxoDFO*, resembling the motif of DFO with four hydroxamic acid groups for binding of the radiometal and four ether linkages to increase the water solubility. Very importantly, the synthesis of this chelator follows a solid phase-assisted approach allowing for an attractive synthetic methodology widening the scope for access to DFO-like chelators in highly efficient synthetic sequences.

The radionuclide zirconium- $89\left({ }^{89} \mathrm{Zr}\right)$ has gained much interest in recent years for applications in nuclear medicine due to its intrinsic properties..$^{1-4}$ In contrast to other commonly utilised PET radionuclides such as fluorine-18 or gallium-68, the physical half-life of ${ }^{89} \mathrm{Zr}\left(\mathrm{t}_{1 / 2}=78.4 \mathrm{~h}\right)$ matches the biological half-life of most antibodies (usually in the order of days). ${ }^{1}$ This enables the antibody coupled zirconium complex to accumulate at the site of the tumor leading to an improvement in signal-to-noise ratios at late time points. Furthermore, good spatial resolution can also be achieved via the use of ${ }^{89} \mathrm{Zr}$ due to its relatively low positron emission 
energy $(B+0.396 \mathrm{MeV}) .^{2}$ To date, the only chelator for complexation of ${ }^{89} \mathrm{Zr}$ utilised in the clinic is the desferrioxamine (DFO) chelator (Figure 1, 1). Preclinical evidence indicates sequestration of ${ }^{89} \mathrm{Zr}$ in radiation sensitive bones due to the release of ${ }^{89} \mathrm{Zr}$ from the chelator leading to reduced signal-to-noise ratios while also raising concerns of the use of the chelator in clinical applications. ${ }^{5-7}$ As a consequence, considerable effort has been placed in the development of new ${ }^{89} \mathrm{Zr}$ chelators with increased in vivo stability.

It has been proposed that the instability of the ${ }^{89} \mathrm{Zr}$-DFO complex is a direct result of the hexadentate nature of DFO, which allows two coordination sites of the metal to be occupied by water molecules. Consequently, in recent years chelators with an increasing denticity have been reported in order to enhance the in vivo stability of ${ }^{89} \mathrm{Zr}$ chelators by saturating the ${ }^{89} \mathrm{Zr}$ coordination sphere. ${ }^{8-17}$ This concept led to the development of DFO*, an octadentate ${ }^{89} \mathrm{Zr}$ chelator which has pioneered the way for innovation in the field of ${ }^{89} \mathrm{Zr}$ chelators and which is now commercially available (Figure 1, 2). ${ }^{8}$ Superior characteristics of the radioimmunoconjugate, ${ }^{89} \mathrm{Zr}$-DFO*-trastuzumab, were established in vivo in comparison to the reference ${ }^{89} \mathrm{Zr}$-DFO-trastuzumab. ${ }^{9}$ Comparable tumor targeting was observed with less unspecific uptake in bones as well as non-targeted tissue and organs. However, the low water solubility of DFO* could potentially impede protein modification protocols. With this in mind, we have designed an octadentate derivative of DFO*, termed oxoDFO*, which incorporates ether linkages aimed to enhance water solubility (Figure 1, 3). Binding of ${ }^{89} \mathrm{Zr}$ to the oxoDFO* derivative mimics that of DFO* with four hydroxamic acid groups.

Unaware of work in progress, a structurally similar ether-based compound was recently published by Codd and co-workers utilising a "microbiological-chemical synthetic" approach. ${ }^{18}$ However, this approach plagued authors with low yielding reactions ( $2 \mathrm{mg}, 21 \%$ ) limiting access and wider application of their ether based

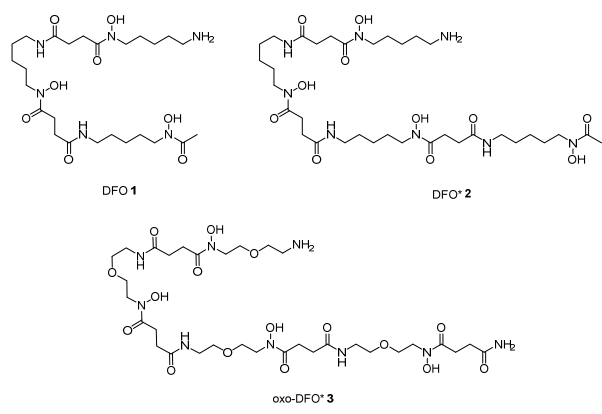

Figure 1: Structures of DFO, DFO* and oxoDFO*.

product. In addition to the investigation of the oxoDFO* structure as a potential ${ }^{89} \mathrm{Zr}$ chelator, we had also intended to explore a solid phase-assisted synthetic approach as an attractive alternative of accessing DFO-like structures. To date, synthetic procedures for the access of DFO-like compounds have solely occurred in the solution phase with the exception of the work reported by Seibold et al. ${ }^{19}$ A solid phase technique was attempted, however, solution phase chemistry proved to be more successful in this case. No solid phase-assisted synthetic methodology has been successfully applied to the synthesis of these types of compounds. The advantages of such an approach include high yielding reactions, simplified multigram scale synthesis, and fewer purification steps. The solid phase methodology allows for a wide scope for the access of similar chelators in the future. Herein, we report the efficient synthesis towards an oxoDFO* chelator capable of conjugation to biomolecules for targeted radiolabelling.

The proposed synthetic route for access to the oxoDFO* consists of two distinct steps; construction of the monomer unit and solid phase-assisted chemistry to build the chelator. Firstly, the monomeric Fmoc-protected ether chains (7) were prepared on a multiple gram scale in six steps with an excellent overall yield of $60 \%$ (Scheme 1). Step-wise nucleophilic substitution of the bromine atoms of $\mathbf{4}$ with potassium phthalimide and tert-butyl 
(benzyloxy)carbamate afforded intermediate 5. Sequential phthalimide deprotection and Fmoc protection of this analogue yielded the Fmoc derivative $\mathbf{6}$. The final step consisted of Boc deprotection followed by consecutive coupling to succinic anhydride which yielded the final monomeric protected hydroxamate unit 7 for solid phase-assisted synthesis of the ${ }^{89} \mathrm{Zr}$ chelator.

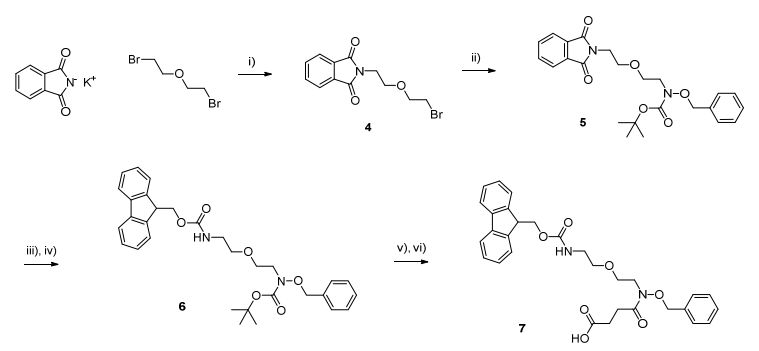

Scheme 1: Synthesis of 10-(benzyloxy)-1-(9H-fluoren-9-yl)-3,11-dioxo-2,7-dioxa-4,10diazatetradecan-14-oic acid (7); i) DMF, $80{ }^{\circ} \mathrm{C}, 48 \mathrm{~h}, \mathrm{~N}_{2}, 89 \%$; ii) tert-butyl (benzyloxy)carbamate, Nal, NaH, DMF, $85^{\circ} \mathrm{C}, 24 \mathrm{~h}, \mathrm{~N}_{2}, 79 \%$; iii) $\mathrm{N}_{2} \mathrm{H}_{2}$, EtOH, $90^{\circ} \mathrm{C}, 90$ mins; iv) FmocCl, $\mathrm{Na}_{2} \mathrm{CO}_{3}$, 1,4-dioxane, $\mathrm{H}_{2} \mathrm{O}, \mathrm{RT}, 3 \mathrm{~h}$, two steps $99 \%$; v) TFA, $20^{\circ} \mathrm{C}, 2 \mathrm{~h}$; vi) DIPEA, succinic anhydride, DMF, RT, $1 \mathrm{~h}, \mathrm{~N}_{2}$, two steps $88 \%$.

For this purpose, the monomeric unit was anchored to the Fmoc deprotected TentaGel S Ram resin (Scheme 2). After further Fmoc deprotection, of our monomer in this case, elongation of the tethered chain occurred using a HATU coupling cocktail using standard Fmoc solid phase peptide synthesis (SPPS). Fmoc deprotection and sequential monomer coupling was completed four times in total to build our resin-bound protected oxoDFO* analogue, 9. Fmoc deprotection and cleavage of the benzyl protected oxoDFO* from the resin resulted in $\mathbf{1 0}$ in $91 \%$ yield used in the next step without further purification. The final oxo chelator, 3, was obtained after palladium catalyzed hydrogenation in $77 \%$ yield.

It has been established within the literature that isothiocyanates (NCS) are able to form stable linkages with monoclonal antibodies through conjugation to the primary amines of Lysine residues. ${ }^{20}$ As a result, addition of an isothiocyanate functionality to oxoDFO* was explored in order to obtain a bifunctional chelating agent (BFCA) for radiopharmaceutical development. The oxoDFO* analogue, 3, was coupled to 4-isothiocyanatobenzoic acid to yield the isothiocyanate derivative 11, oxoDFO*-pPhe-NCS (Scheme 2). The isothiocyanate derivative was isolated after preparative HPLC in a high purity ( $\geq 95 \%)$ as determined by LC analysis. Low yields of this reaction could be due to the lack of selectivity between the two terminal groups but could potentially be improved by attempting to couple 4isothiocyanatobenzoic acid while resin bound. OxoDFO*-pPhe-NCS 11, is ideally suited for coupling to monoclonal antibodies for applications in immuno-PET imaging.

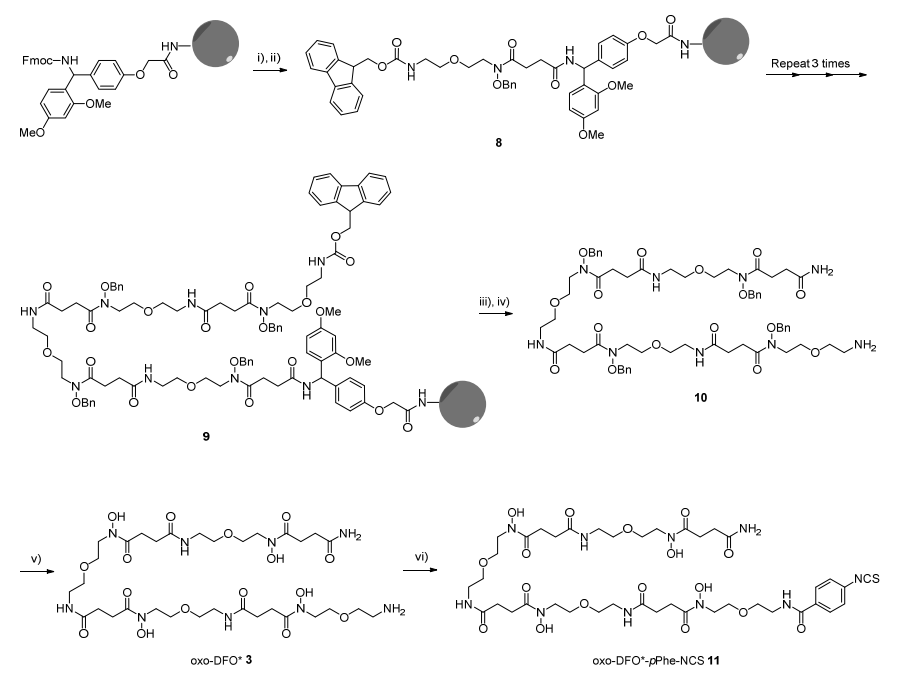


Scheme 2: Solid phase-assisted synthesis of oxoDFO* analogue, 3, and its NCS derivative oxoDFO*-pPhe-NCS, 11.; i) Deprotection: 20 vol. \% piperidine/DMF ii) Coupling: 7, HATU, DIPEA/2,6-lutidine/DMF (3.5/3.5/93 : v/v/v) iii) Deprotection: 20 vol. \% piperidine/DMF; iv) Cleavage: TFA/TIPS/ $\mathrm{H}_{2} \mathrm{O}$ (38/1/1 : v/v/v), 91\%; v) 10\% Pd/C, $\mathrm{H}_{2}, 5$ bar, RT, 4 h, 77\%; vi) 4isothiocyanatobenzoic acid, HATU, DIPEA, DMF, $12 \mathrm{~h}, \mathrm{RT}, \mathrm{N}_{2}, 15 \%$.

In order to demonstrate the feasibility of radiolabelling, complexation of nat $\mathrm{Zr}$ (IV) to the ligand, oxoDFO*, 3, was examined. Complexation of nat $\mathrm{Zr}$ (IV) was achieved via a previously reported procedure ${ }^{8}$ at $\mathrm{RT}$ and neutral $\mathrm{pH}$ which are optimal reaction conditions for the radiolabelling of sensitive biomolecules (e.g., mAb). HRMS data supporting the formation of the desired complex $\left(\mathrm{m} / \mathrm{z}_{\text {calc. }}=934.2706[\mathrm{M}+\mathrm{Na}]^{+}, \mathrm{m} / \mathrm{z}_{\text {obs. }}=934.2706[\mathrm{M}+\mathrm{Na}]^{+}\right)$.

The hydrophobicity of oxoDFO*, 3, oxoDFO*-pPhe-NCS, 11, and [ ${ }^{\text {nat }} \mathrm{Zr}$-3] were determined via the shake flask method with distribution coefficients $\left(\log D_{7.4}\right)$ of $-1.5 \pm 0.2,-1.2 \pm 0.1$ and -2.1 \pm 0.1 respectively. As anticipated, oxoDFO* derivatives exhibited a remarkably increased hydrophilicity in comparison to the corresponding DFO* $\left(\log D_{7.4}=-0.4397\right)$ analogue. Furthermore, our oxoDFO*analogue, 3, was highly water soluble in the absence of co-solvents (approx. $>50 \mathrm{mg} / \mathrm{mL}$ ).

\section{Conclusions}

Research and development into new chelators for applications in ${ }^{89} \mathrm{Zr}$-PET imaging has undergone remarkable growth in recent years. Recently reported octadentate chelators provide an improvement on the in vivo stability of ${ }^{89} \mathrm{Zr}$ chelators. Although a set of requirements exist for a potential (radio)metal chelator to make it to market, it is crucial that synthetic targets can be obtained in facile, high yielding synthetic sequences and have the potential to be accessed easily on a multi-gram scale. Our solid phase-assisted approach presents a method which meets these requirements. We have demonstrated this concept through a highly efficient solid phase-assisted synthetic methodology for the preparation of an ether based DFO-like chelator. The octadentate oxoDFO* chelator, 3, incorporates four ether chains resulting in a highly hydrophilic chelator $\left(\log D_{7.4}=-1.5 \pm 0.2\right)$. The prepared isothiocyanato BFCA, 11, maintains its hydrophilicity $\left(\log D_{7.4}=-1.2 \pm 0.1\right)$ and highlights the potential applications of the oxoDFO* structure for bioconjugations and applications in immuno-PET imaging. The successfully employed solid phase-assisted approach should inspire further the use of this methodology in the development of future DFO-like target structures to ensure highly efficient syntheses for clinical applications of these exciting new class of ${ }^{89} \mathrm{Zr}$ chelators. As discussed with Codd and co-workers, the radiolabelling of oxoDFO* with ${ }^{89} \mathrm{Zr}$ will be published in due course.

\section{Conflicts of interest}

There are no conflicts to declare.

\section{Acknowledgements}

This work was financially supported by the Swiss National Science Foundation (Professorships N PP00P2_133568 and PPOOP2_157545 to G.G. as well as Grant SNSF 205321_157216 to G.G. and T.L.M) and has received support under the program "Investissements d'Avenir " launched by the French Government and implemented by the ANR with the reference ANR10-IDEX-0001-02 PSL (G.G.). The authors thank Carla Gotzmann for help towards the synthesis of one of the precursors.

\section{Notes and references}

1 Y. Zhang; H. Hong, W. Cai, Current radiopharmaceuticals, 2011, 4, 131. 
2 G. Van Dongen, M. Huisman, R. Boellaard, N. Hendrikse, A. Windhorst, G. Visser, C. Molthoff, D. Vugts, The Quarterly Journal of Nuclear Medicine and Molecular Imaging, 2015, 59, 18.

3 M. A. Deri, B. M. Zeglis, L. C. Francesconi, J. S. Lewis, Nuclear medicine and biology, 2013, 40, 3.

4 B. D. Wright, S. E. Lapi, Journal of Nuclear Medicine, 2013, 54, 1171.

5 G. Fischer, U. Seibold, R. Schirrmacher, B. Wängler, C. Wängler, Molecules, 2013, 18, 6469.

6 B. M. Zeglis, P. Mohindra, G. I. Weissmann, V. Divilov, S. A. Hilderbrand, R. Weissleder, J. S. Lewis, Bioconjugate chemistry, 2011, 22, 2048.

7 D. S. Abou, T. Ku, P. M. Smith-Jones, Nuclear medicine and biology, 2011, 38, 675.

8 M. Patra, A. Bauman, C. Mari, C. A. Fischer, O. Blacque, D. Häussinger, G. Gasser, T. L. Mindt, Chemical Communications, 2014, 50, 11523.

9 D. J. Vugts, C. Klaver, C. Sewing, A. J. Poot, K. Adamzek, S. Huegli, C. Mari, G. W. Visser, I. E. Valverde, G. Gasser, European journal of nuclear medicine and molecular imaging, 2017, 44, 286.

10D. N. Pandya, S. Pailloux, D. Tatum, D. Magda, T. J. Wadas, Chemical Communications, 2015, 51, 2301.

11E. Boros, J. P. Holland, N. Kenton, N. Rotile, P. Caravan, ChemPlusChem, 2016, 81, 274.

12 L. Allott, C. Da Pieve, J. Meyers, T. Spinks, D. Ciobota, G. Kramer-Marek, G. Smith, Chemical Communications, 2017, 53, 8529.

13C. Buchwalder, C. Rodríguez-Rodríguez, P. Schaffer, S. K. Karagiozov, K. Saatchi, U. Häfeli, Dalton Transactions, 2017, 46, 9654.

14 J. Rousseau, Z. Zhang, G. M. Dias, C. Żhang, N. Colpo, F. Bénard, K.-S. Lin, Bioorganic \& Medicinal Chemistry Letters, 2017, 27, 708.

15 W. Tieu, T. Lifa, A. Katsifis, R. Codd, Inorganic Chemistry, 2017, 56, 3719.

16S. E. Rudd, P. Roselt, C. Cullinane, R. J. Hicks, P. S. Donnelly, Chemical Communications, 2016, 52, 11889.

17 M. A. Deri, S. Ponnala, P. Kozlowski, B. P. Burton-Pye, H. T. Cicek, C. Hu, J. S. Lewis, L. C. Francesconi, Bioconjugate chemistry, 2015, 26, 2579.

18T. Richardson-Sanchez, W. Tieu, M. P. Gotsbacher, T. J. Telfer, R. Codd, Organic \& Biomolecular Chemistry, 2017, 15, 5719.

19U. Seibold, B. Wängler, C. Wängler, ChemMedChem 2017, 12, 1555.

20 G. Barbarella, M. Zambianchi, O. Pudova, V. Paladini, A. Ventola, F. Cipriani, G. Gigli, R. Cingolani, G. Citro, Journal of the American Chemical Society, 2001, 123, 11600. 